\title{
“Just a Job?" An Assessment of Precarious Employment Trajectories by Gender Among Young People in the U.S.
}

\author{
Skye Allmang \\ Todd Franke
}

\begin{abstract}
Precarious employment is on the rise in the United States. Research suggests that young workers are more likely than older workers to be in precarious work. Yet much remains unknown regarding the precarious nature of employment experienced by young workers, despite evidence of the importance of this period for long-term employment opportunities. To address this gap in knowledge, this study used a nationallyrepresentative, longitudinal dataset to create a multi-dimensional measure of precarious employment, and assessed precarious employment trajectories over time for young women and men. Findings revealed that, while there were significant shifts in levels of precarity over time for both males and females, patterns differed by gender. Overall, higher percentages offemales than males remained concentrated at the semi-precarious level over time - meaning that they did not move further into or out of precarious employment-while higher percentages of males became either much more precarious or much less precarious over time. These findings challenge the common assumption that young people generally move out of low-wage or otherwise "bad" jobs over time, and suggest that there is a need for additional attention to gendered patterns in job quality among young people. Social workers have an important role to play in helping young people enter non-precarious jobs, and in engaging in advocacy to improve the quality of jobs available.
\end{abstract}

Keywords: Precarious employment; gender; emerging adults.

It is widely recognized that women and men in the United States have disparate employment experiences. While researchers have identified signs of progress over the past several decades, they have also documented a host of persistent challenges, including gender wage inequality (Blau \& Kahn, 2007; Goldin et al., 2017), occupational segregation (Cech, 2016; Hegewisch et al., 2010), hostile work environments (Alterman et al., 2013), and discrimination in accessing opportunities for training and advancement (Shaffer et al., 2000). In addition, a growing body of literature has called attention to the gendered nature of precarious work, or work that is characterized by multiple dimensions of instability (Vosko et al., 2009).

Less well-tended to, however, has been the topic of gender differences in precarious employment among young people. While studies show that there is a high number of young people in precarious employment (Kalleberg, 2019), and theoretical and empirical studies have highlighted the importance of early employment experiences for long-term wage and employment opportunities (e.g., Glatt \& Wunnava, 2018), much remains unknown regarding young people's experiences in precarious employment during the early stages of their careers. In other words, at this time, are most young men and women moving away from precarity, moving further into precarity, avoiding precarious employment altogether,

Skye Allmang, PhD, MSW, MPP, Postdoctoral Associate, Rutgers School of Social Work, New Brunswick, NJ. Todd M. Franke, PhD, MSW, Professor of Social Welfare, UCLA Luskin School of Public Affairs, Los Angeles, CA.

Copyright @ 2020 Authors, Vol. 20 No. 1 (Spring 2020), 152-171, DOI: 10.18060/23600

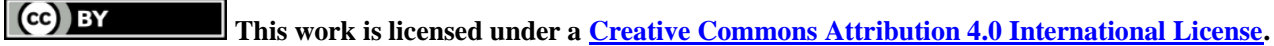


or remaining stuck in precarious employment over time? Understanding these trajectories could inform our current understanding of whether a job at the beginning of one's career really is "just a job" - or whether experiences of remaining stuck in precarious employment reflect and reinforce broad patterns of gender inequality.

This study aims to address this current gap in knowledge through the assessment of precarious employment trajectories among emerging adults in the United States. After reviewing the relevant literature, this article describes the methods used to group young people into precarious employment categories, and explores the results regarding whether and how young men and women moved over time. The article concludes with a discussion of the implications of the study's findings for research, policy, and practice.

\section{Precarious Employment in the United States}

Since the 1970s, globalization, changes in technology, and the weakening of unions, among other economic and social forces, have transformed employment relations in the United States. One indication of this transformation is the rise in precarious employment, or "employment that is uncertain, unpredictable, and risky from the point of view of the worker" (Kalleberg, 2009, p. 2). This term was chosen as the focus of this study, instead of other similar terms such as "atypical employment" or "bad jobs" because it "represents a series of questions for the employment structure... [and] represents in effect a research program or agenda that can be used to open up analysis" (Vosko et al., 2009, p. 9). In other words, utilizing the concept of precarious employment calls attention to the transformation of employment relations that has recently taken place, and highlights particular job characteristics that researchers can use to measure these changes. Specifically, following Rodgers (1989), this study conceptualizes precarious employment as a multi-dimensional construct, characterized by four measures of job quality: instability or high risk of job loss, lack of control over one's work, lack of workplace and employer protections, and low wages.

There is a growing body of literature on precarious employment (e.g., Benach et al., 2016; Cranford et al., 2003; Quinlan et al., 2001). Precarious employment is often captured through the assessment of one of the job characteristics outlined by Rodgers, such as the likelihood that a person will lose his or her job. For example, the 2012 General Social Survey included the question, "Thinking about the next 12 months, how likely do you think it is that you will lose your job or be laid off--very likely, fairly likely, not too likely, or not at all likely?" Overall, findings from the survey indicated that approximately $11.2 \%$ of workers answered that they expected to lose their jobs (U.S. Bureau of Labor Statistics [BLS], 2015, para. 8).

Two other dimensions of precariousness are wages and the level of control that workers have over their work schedules. While there are various ways to measure low-wage work, Bernhardt and Osterman's analyses of the U.S. Current Population Survey data from 2013 found that $39 \%$ of U.S. workers earned less than $\$ 15$ an hour (Bernhardt \& Osterman, 2017). Research on workers' control over their work schedules has also uncovered high levels of precariousness. Lambert and Henly (2014) analyzed work schedule data from the 1997 National Longitudinal Survey of Youth and found that about half of the hourly 
workers and $35 \%$ of non-hourly workers reported that their employer decides when they start and finish work.

Lastly, the prevalence of precarious work may be captured based on the extent to which workers are able to obtain health insurance and retirement benefits through their employers (Kalleberg, 2000). This has been particularly true in the United States, where these benefits have traditionally been accessed through employers. An analysis of the March 2017 Current Population Survey, for example, found that $74 \%$ of noninsured workers had an employer that did not offer health insurance coverage (Kaiser Family Foundation, 2017).

These dimensions of precarity, when measured separately, provide critical insight into employment patterns in the United States. Researchers are also beginning to assess precarious employment using new approaches which capture multiple dimensions in a single measure (e.g., Cranford \& Vosko, 2006; Frade et al., 2004; García-Pérez et al., 2017). Much remains to be understood, however, to improve our understanding of precarious employment, in light of what has been described as "the wide gap between the scale of precarious work and social scientific understanding of it more generally" (Kalleberg \& Vallas, 2018, p. 2).

\section{Gender and Precarious Employment}

Vosko et al. (2009) note that "[t]he current period is... often characterized as an era of both gendered labour market change and concern about persistent inequality and precariousness" (p. 1). A growing body of research has documented a range of evidence of the overrepresentation of women in precarious employment.

Information from the U.S. Bureau of Labor Statistics provides insight into gender differences in the number of workers in contingent-or temporary-work. Results from the 2005 Contingent Worker Supplement, which was designed to capture information on the number and characteristics of contingent worker in the United States, indicated that contingent workers in the United States were slightly more likely to be female than male, (49 percent versus 47 percent) (BLS, 2005).

In addition, an analysis of the Canadian context by Vosko and Clark (2009) found that "across all forms of paid employment, but especially part-time forms, prime working age women were concentrated in sales and services occupations, whereas men were spread more evenly across occupations" (p. 33). In the United States, researchers have similarly found that "employment precariousness is distributed in ways that reflect and reinforce gender and racial/ethnic inequalities in the labor market" (Carré \& Heintz, 2009, p. 57).

Minimum wage research suggests that women are not only more likely to enter lowpaying work - they are also more likely to "get stuck" in it (Boushey, 2005). As demonstrated in Boushey's seminal study of minimum wage work, while over a third of workers between the ages of 25 and 54 remained stuck in low-wage work over a period of three years, women had a lower probability of moving out of low-wage work than men .

Finally, previous research has highlighted the ways in which work-life policies disadvantage women, making it hard to move up over time. Comparative studies have found that although these policies — such as parental leave, flexible scheduling, and child 
care policies - have been found to support women's attachment to the labor force, they have also been found to reinforce occupational segregation and the gender wage gap (Mandel \& Semyonov, 2005). While there is a wealth of research on this topic from various countries, such as Germany (e.g., Chirkova, 2019) and Sweden (Haas \& Hwang, 2008), much remains to be understood regarding the complex ways in which these policies may affect men and women's decision-making and employment outcomes throughout the life course (Hegewisch \& Gornick, 2011).

\section{Young People in Precarious Employment}

Though there is a considerable body of research on gender inequalities in employment, and increasingly on the intersection of gender and precarious employment, there remains a lack of research focusing specifically on gender and precarious employment trajectories among young people in the United States, despite theory and empirical evidence on the importance of early employment experiences. According to developmental theory, when people are approximately 18 to 29 years old, they are exploring various possibilities related to school, work, and relationships, during a stage that Arnett (2000) called "emerging adulthood." This developmental stage is generally considered to be distinct from adolescence and the initial stages of full-fledged adulthood, in that emerging adults are generally done with secondary school and are no longer considered minors, but do not yet have stability in many realms, including housing, romantic relationships, or work. Compared to adolescence, when young people are undertaking "transient and tentative explorations," emerging adulthood is a time of more serious and focused explorations related to employment (Arnett, 2000, p. 473).

Existing empirical research suggests that employment experiences during this stage can have important implications for the person in the future (Osgood et al., 2005). Specifically, studies indicate that early unemployment and underemployment experiences can have an economic "scarring effect" (Glatt \& Wunnava, 2018, p. 51; Kletzer \& Fairlie, 1999; Mroz \& Savage, 2006). This effect is particularly strong over the first few years after an extended period of unemployment. An analysis utilizing the 1979 National Longitudinal Survey of Youth data, for example, found that an unemployment spell of 26 weeks reduced wages by about $4.6 \%$ a year later, and $2.9 \%$ up to three years later (Mroz \& Savage, 2006). There are several potential reasons for this scarring effect, including reduced motivation, fewer opportunities to develop new skills, and the potential "signaling" to employers that may come from a period of unemployment (Glatt \& Wunnava, 2018).

In addition to the growing body of research on the importance of early employment experiences for young people, there is also a growing body of research on gender differences in employment experiences during this time, as well as the potential repercussions from these experiences for decision-making and opportunities throughout the life course. For example, a qualitative study from Australia found that being in precarious employment impacted women differently than men, in that precarious employment appeared to play a role in reinforcing gender imbalances in household labor. In addition, findings from the study indicated that early experiences of precarious employment were related to "reproductive insecurity," or constrained decision-making around family formation (Chan \& Tweedie, 2015, p. 6). 
Similarly, there is evidence that these differences are not ameliorated by postsecondary education. A recent study of trends in precarious employment in the United States found that “young women's employment quality declined, especially after 2001, in all four education groups [for those with no credentials, a high school diploma, some college, and a college degree]. The declines were substantial, averaging 12 percentage points in a 15-year period" (Hout, 2019, p. 30). These findings on the role of education and the long-term impacts of precarious employment suggest that gender differences in precarious employment are not due to young people's preferences or differences in education. However, much remains unknown regarding the association between gender and precarious employment trajectories among young people in the United States.

Based on these gaps in current knowledge, this study aimed to illuminate trajectories of employment precarity experienced by young workers, and to identify differences and similarities in these trajectories by gender. Specifically, this study sought to answer two main research questions, using a multi-dimensional measure of precarious employment: (1) What were the percentages of young women and men in precarious employment at the first time period, when respondents were between the ages of 18 and 26? (2) What were the similarities and differences in precarious employment trajectories by gender, from the first time period to six years later when respondents were 24 to 32 years old? Based on the previous literature, it was hypothesized that somewhat higher percentages of young women than men would be in precarious employment at the initial time point. In addition, it was hypothesized that higher percentages of women would "get stuck" in precarious employment over time.

\section{Method}

\section{Data Source and Sample}

This study utilized data from the National Longitudinal Study of Adolescent to Adult Health (Add Health, n.d.), a nationally-representative, longitudinal study of young people in the United States (Harris, 2009). Data from three waves were used: Wave I (collected in 1994-1995, when respondents were in grades 7 through 12), Wave III (collected in 20012002, when respondents were 18 to 26 years old), and Wave IV (collected in 2008, when respondents were 24 to 32 years old). Wave I provided demographic information for the study, while data from Waves III and IV captured two points within the period of emerging adulthood. All research activities for the study were approved by the Institutional Review Board of the University of California, Los Angeles.

Because the individuals in the Add Health study were selected with unequal probability, adjustment was necessary to ensure that estimates were not biased (Chen \& Chantala, 2014). Overall, the study sample was restricted to respondents who had all study weights, strata, and primary sampling units (PSUs). Respondents were excluded if they were missing employment data, or if they worked less than 10 hours a week, during Waves III or IV. The total sample consisted of 5,976 (unweighted) young workers, representing a population of 10,669,830 (weighted) young workers across the United States. 
The sample was approximately $56 \%$ male and $44 \%$ female, which roughly resembled the gender breakdown for workers between the ages of 16 and 24 in the United States (Toossi, 2002). The average age of men and women in the sample was 22 years old (at Wave III). Men and women appeared to differ slightly in terms of their age, race/ethnicity, and level of education. For example, a higher proportion of men had a high school diploma or GED, while a higher proportion of women had a bachelor's degree at Wave III. Analyses of Pearson's $r$ and Cramer's V indicated, however, that while these differences were statistically significant, the extent of these differences appeared to be quite small. This information is presented in Table 1.

Table 1. Sociodemographic Characteristics of the Study Sample (unweighted)

\begin{tabular}{l|c|c:c|c}
\hline & & $\begin{array}{c}\text { Female } \\
(\mathrm{n}=2,973)\end{array}$ & $\begin{array}{c}\text { Total } \\
(\mathrm{n}=5,976)\end{array}$ & $\mathrm{r} / \mathrm{V}$ \\
\hline Age* (average years) & Male (n=3,003) & 22.0 & 22.1 & -.09 \\
\hline Race/Ethnicity* & 22.3 & & & .07 \\
Asian or Pacific Islander (NH) & $6.9 \%$ & $5.7 \%$ & $6.3 \%$ & \\
Black (NH) & $15.8 \%$ & $20.9 \%$ & $18.4 \%$ & \\
Hispanic or Latino & $17.0 \%$ & $15.2 \%$ & $16.1 \%$ & \\
Other (NH) & $2.8 \%$ & $2.0 \%$ & $2.4 \%$ & \\
White (NH) & $57.5 \%$ & $56.2 \%$ & $56.9 \%$ & \\
\hline Level of education (Wave III)* & & & & .12 \\
Less than high school & $8.6 \%$ & $4.2 \%$ & $6.4 \%$ & \\
High school diploma or GED & $73.7 \%$ & $70.9 \%$ & $72.3 \%$ & \\
Vocational certificate & $6.8 \%$ & $9.0 \%$ & $7.9 \%$ & \\
Bachelor's degree & $10.3 \%$ & $14.9 \%$ & $12.6 \%$ & \\
Master's degree & $0.4 \%$ & $0.7 \%$ & $0.5 \%$ & \\
PhD/JD/MD & $0.2 \%$ & $0.3 \%$ & $0.3 \%$ & \\
\hline
\end{tabular}

$* \mathrm{p}<.05 \mathrm{r} \rightarrow$ Pearson, $\mathrm{V} \rightarrow$ Cramer

$\mathrm{NH}=$ Non-Hispanic

\section{Measures}

As mentioned in the previous section, we followed researchers such as Rodgers (1989) and Vosko et al. (2009) in conceptualizing precarious employment as a multidimensional construct, identifiable based on the assessment of job characteristics. The four measures of job characteristics described by Rodgers (1989) were used for this study: job security/insecurity, control over one's work schedule, employer-provided benefits, and wages.

\section{Job (In)Security}

To assess job security, the respondent's major occupational group (the first two digits of the six-digit 1998 Standard Occupational Classification code) was recoded to represent the likelihood of being employed in "alternative work arrangements," or nonstandard positions, a category that includes temporary help agency workers, on-call workers, contract workers, and independent contractors. This information was obtained from an analysis by Lawrence Katz and Alan Krueger of the U.S. Bureau of Labor Statistics' Contingent Worker Survey (CWS) from 2005 (Katz \& Krueger, 2016). In total, 22 
occupational categories were recoded into percentages, representing the percentage of workers from each occupational category that were employed in alternative work arrangements from the 2005 CWS, which ranged from 3.0 to 31.2.

\section{Control Over One's Work Schedule}

Whether the respondent had control over his or her work schedule was captured through the question, "Which of these categories best describes the hours you work at this job?" Responses included: "regular day shift," "regular evening shift," "regular night shift," "shift that rotates, that is it changes periodically from day to evening or night," "split shift that consists of two distinct periods each day," and "irregular schedule or hours." The response "irregular schedule or hours" was considered to represent lack of control over one's work schedule.

\section{Employer-provided Benefits}

The measure of whether the respondent received benefits from his or her employer was assessed using the answer to the question: "which of the following currently describes your current health insurance situation?" The response "you get insurance through work" was used to represent whether the person received health insurance through their employer.

\section{Wages}

Lastly, wages were measured by the question, "Now think about your personal earnings. In \{year of the survey\}, how much income did you receive from personal earnings before taxes, that is, wages or salaries, including tips, bonuses, and overtime pay, and income from self-employment?" Responses were grouped into eight categories: \$1 to $\$ 10,000, \$ 10,001$ to $\$ 14,999, \$ 15,000$ to $\$ 19,999, \$ 20,000$ to $\$ 29,999$, " 30,000 to $\$ 39,999, "$ " $\$ 40,000$ to $\$ 49,999, "$ " $\$ 50,000$ to $\$ 74,999$," and " $\$ 75,000$ and above."

\section{Analytic approach}

To assess underlying patterns that could be used to identify various levels of precarious employment, latent class analysis - a technique to measure unobserved (or latent) groups through the analysis of observed variables (McCutcheon, 1987) - was conducted using Mplus (Muthén \& Muthén, 1998). The modeling process began with a one-class model, with the number of classes increasing until there was no additional improvement in the model. Fit indices (specifically, the Bayesian information criterion and adjusted Bayesian information criterion, as well as entropy measures), were used to assess the goodness-offit for each model, and to choose the most appropriate grouping.

Latent class analysis (LCA) was conducted using the four job quality variables from Wave III, and then repeated using the same four job quality variables from Wave IV. LCA was conducted first with the total sample (males and females), and then separately for males and females. The groups from Wave III were used to answer the first research question on the percentages of young women and men in precarious employment at the first time period, when they were between the ages of 18 and 26 .

In order to answer the second research question (What were the similarities and differences in precarious employment trajectories by gender, from the first time period to 
six years later when respondents were 24 to 32 years old?), crosstabs were conducted for the total sample, as well as for males and females separately. Pearson correlations and Cramer's V were included in order to assess the strength of the association between gender and job characteristics. From there, Bowker's (1948) tests for symmetry were used to assess internal changes from Wave III to Wave IV. Bonferroni post-hoc tests (Dunn, 1961) were then conducted, which generated multiple comparisons of the three possible pairwise shifts that occurred from Wave III to Wave IV. Information generated from these tests was used to assess employment trajectories for the overall sample, as well as for males and females separately. Throughout, all statistical analyses were two-tailed.

\section{Results}

The following section presents the results of the study starting with descriptive statistics. Next, levels of precarity at Wave III (when the study respondents were between the ages of 18 and 26) and Wave IV (ages 24 to 32) are summarized. Finally, results from our assessment of employment trajectories are described.

Table 2. Wave III \& IV Job Characteristics by Gender (unweighted)

\begin{tabular}{|c|c|c|c|c|c|}
\hline & \multicolumn{3}{|c|}{$\%$} & \multirow[b]{2}{*}{$\begin{array}{c}\text { Test } \\
\text { Statistic }\end{array}$} & \multirow[b]{2}{*}{$\mathrm{r} / \mathrm{V}$} \\
\hline & $\begin{array}{c}\text { Male } \\
(n=3,003)\end{array}$ & $\begin{array}{c}\text { Female } \\
(\mathrm{n}=2,973)\end{array}$ & $\begin{array}{c}\text { Total } \\
(\mathrm{n}=5,976)\end{array}$ & & \\
\hline $\begin{array}{l}\text { Wave III Variables } \\
\text { Probability of job insecurity (average) } \\
\text { No employer-provided health insurance } \\
\text { Irregular work schedule } \\
\text { Wages } \\
\text { Less than } \$ 10,000 \\
\$ 10,001-14,999 \\
\$ 15,000-19,999 \\
\$ 20,000-29,999 \\
\$ 30,000-39,999 \\
\$ 40,000-49,999 \\
\$ 50,000-74,999 \\
\text { Above } \$ 75,000\end{array}$ & $\begin{array}{c}39.7 \\
10.9 \\
14.4 \\
21.6 \\
8.1 \\
3.0 \\
1.7 \\
0.7 \\
\end{array}$ & $\begin{array}{c}9.7 \\
59.8 \\
8.5 \\
\\
50.1 \\
13.3 \\
14.3 \\
16.2 \\
4.2 \\
1.1 \\
0.5 \\
0.2 \\
\end{array}$ & $\begin{array}{c}10.7 \\
56.8 \\
9.1 \\
\\
44.9 \\
12.1 \\
14.3 \\
18.9 \\
6.2 \\
2.1 \\
1.1 \\
0.5 \\
\end{array}$ & $\begin{array}{c}13.23 * \\
21.51 * \\
1.8 \\
155.39 *\end{array}$ & $\begin{array}{l}-.16 \\
.06 \\
.02 \\
.16\end{array}$ \\
\hline $\begin{array}{l}\text { Wave IV Variables } \\
\text { Probability of job insecurity (average) } \\
\text { No employer-provided health insurance } \\
\text { Irregular work schedule } \\
\text { Wages } \\
\text { Less than } \$ 10,000 \\
\$ 10,001-14,999 \\
\$ 15,000-19,999 \\
\$ 20,000-29,999 \\
\$ 30,000-39,999 \\
\$ 40,000-49,999 \\
\$ 50,000-74,999 \\
\text { Above } \$ 75,000 \\
\end{array}$ & $\begin{array}{c}11.5 \\
35.4 \\
11.5 \\
\\
6.7 \\
3.0 \\
4.8 \\
17.1 \\
21.5 \\
15.7 \\
20.6 \\
10.7 \\
\end{array}$ & $\begin{array}{c}9.1 \\
41.0 \\
8.4 \\
\\
12.2 \\
5.0 \\
7.6 \\
23.0 \\
21.5 \\
13.7 \\
13.1 \\
4.0 \\
\end{array}$ & $\begin{array}{c}10.3 \\
38.2 \\
10.0 \\
\\
9.4 \\
4.0 \\
6.2 \\
20.0 \\
21.5 \\
14.7 \\
16.9 \\
7.4 \\
\end{array}$ & $\begin{array}{c}15.33^{*} \\
18.76^{*} \\
16.00^{*} \\
257.08 *\end{array}$ & $\begin{array}{r}-.19 \\
.06 \\
.05 \\
.21\end{array}$ \\
\hline
\end{tabular}

Note. Test statistic was generated from a t-test or chi-squared test as appropriate.

$* p<.05 \mathrm{r} \rightarrow$ Pearson, $\mathrm{V} \rightarrow$ Cramer 


\section{Descriptive Statistics}

The overall job characteristics of the young men and women in the sample at Waves III and IV are presented in Table 2. Males and females were statistically different on each of the four job characteristics at both waves, except for one measure - the irregular work schedule at Wave III. Women were slightly better off than men in terms of job insecurity, but worse off in terms of access to employer-provided health insurance, an irregular work schedule, and wages at both waves.

\section{Levels of Precarity at Wave III (Ages 18 to 26) and Wave IV (Ages 24 to 32)}

LCA was conducted for the overall sample, as well as for men and women separately, in order to assess levels of precarious employment at Wave III and Wave IV. At each wave, statistical measures of model fit (BIC, Adjusted BIC, and entropy measures) suggested that the three-class solution (representing least precarious, semi-precarious, and most precarious groups) best fit the data (Nylund et al., 2007).

Figure 1 presents the various levels of precarity for the overall sample, and for males and females separately. Just under half of the overall sample fell into the semi-precarious employment group at Wave III, while about $39 \%$ were in the least precarious category, and about $12 \%$ were in the most precarious category. Slightly higher percentages of females than males were in the semi-precarious employment category, and slightly lower percentages of women were found to be in the most precarious category.

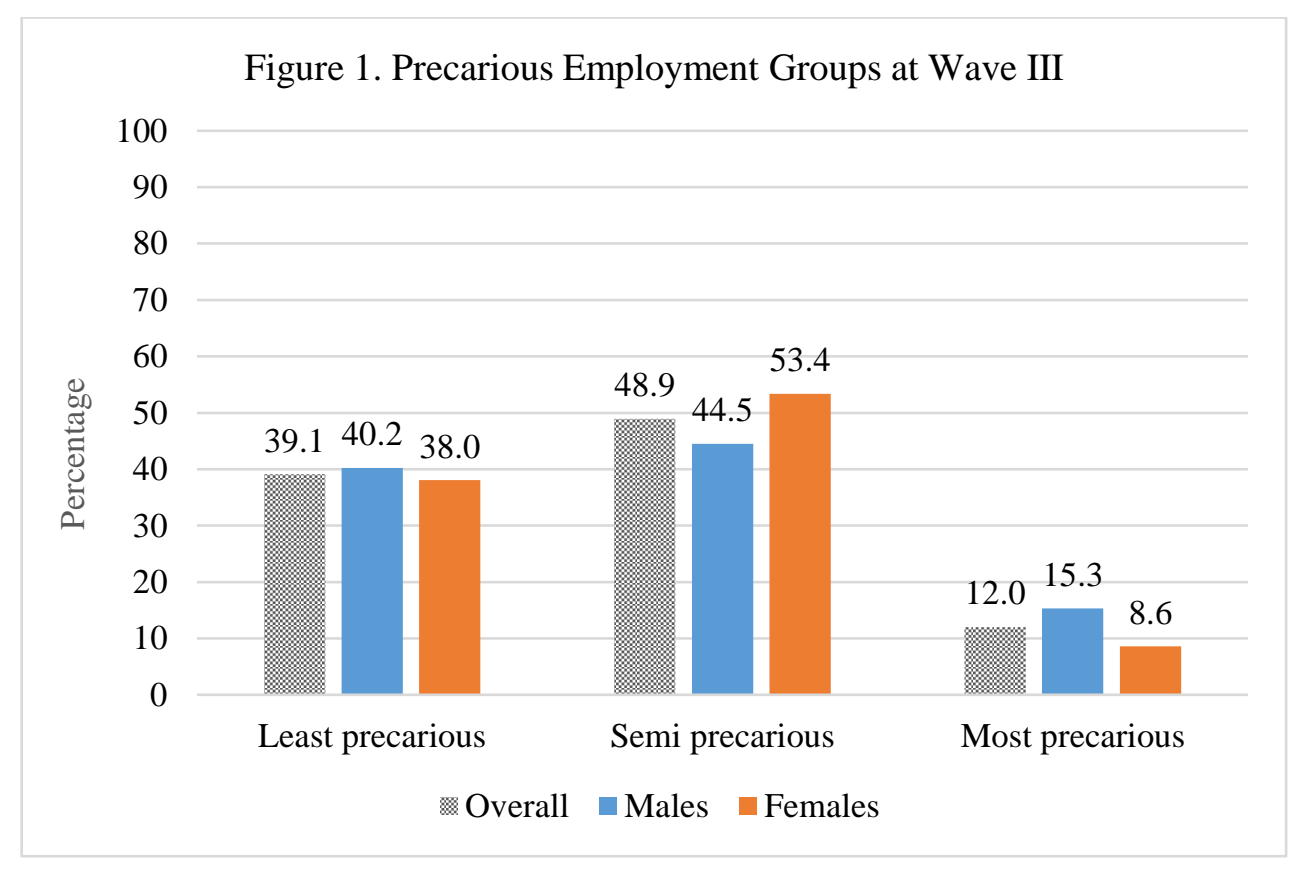

Figure 2 presents the levels of precarity at Wave IV for the total sample, for males, and for females. The overall trend from Wave III to IV was a reduction in precarity (in other 
words, an improvement in job quality). This was the case for the overall sample, as well as the separate analyses for males and females.

There were notable differences, however, in the percentages of young people who remained in semi-precarious employment at both points in time. While the percentage of respondents in the overall sample in semi-precarious work decreased from about $49 \%$ at Wave III to $31 \%$ at Wave IV, and the number of males in semi-precarious employment decreased from about $45 \%$ at Wave III to $16 \%$ at Wave IV, the number of females in semiprecarious employment decreased from about $53 \%$ to about 36 percent. Therefore, higher percentages of females than males appeared to remain in semi-precarious employment from Wave III to Wave IV.

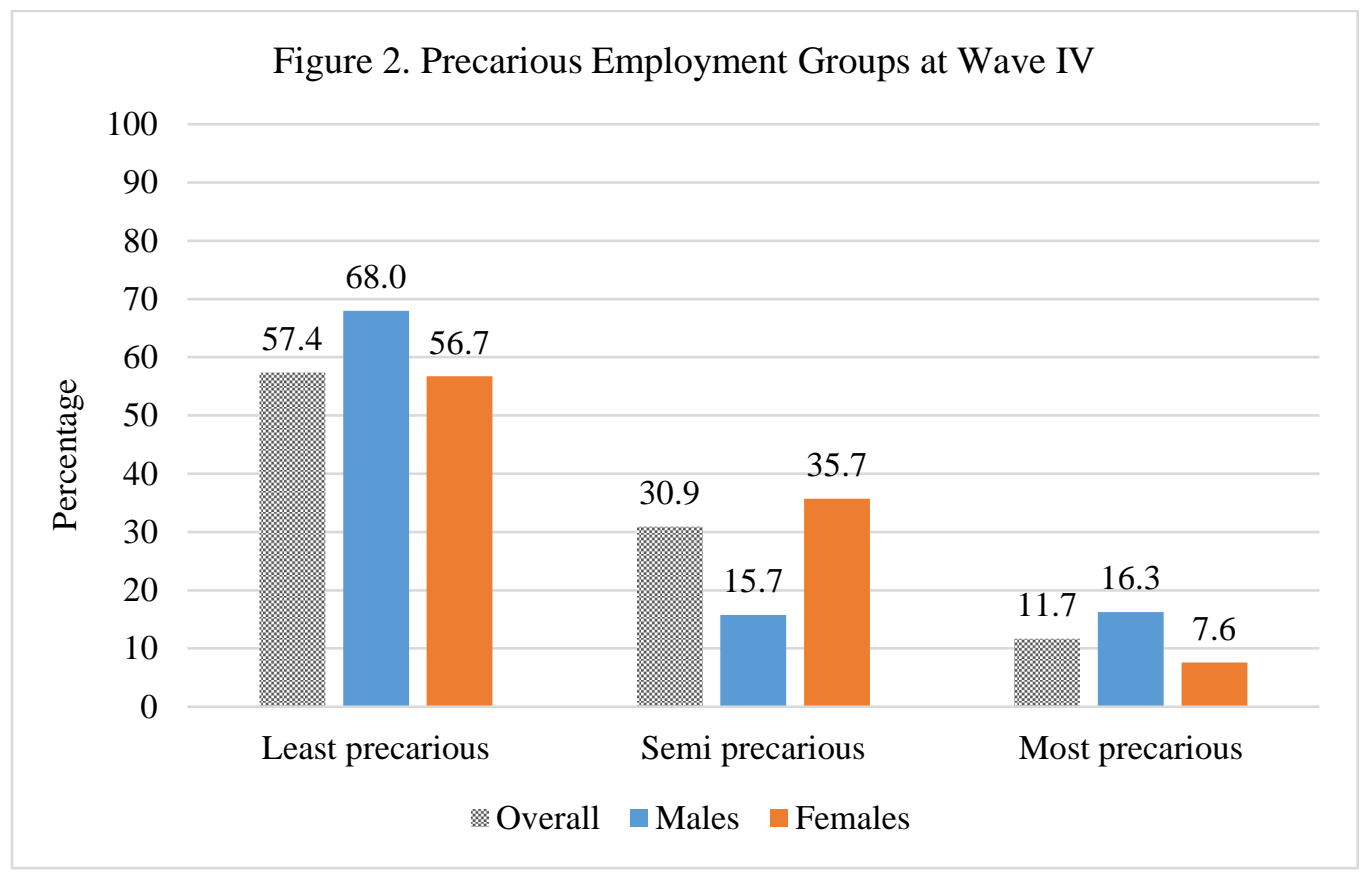

\section{Assessing Employment Trajectories}

Table 3 displays information on employment trajectories from Wave III to Wave IV, first for the overall sample, followed by the trajectories for males and females. The people on the diagonal (who were either least precarious, semi-precarious, or most precarious at both points in time) did not change. Among those who did not change, approximately $26 \%$ of the overall sample was in the least precarious group at both points in time. This group is represented in light gray. Slightly more males (about 32\%) than the overall sample were in the least precarious groups at both points in time, while slightly fewer females (about $25 \%$ ) were in the least precarious group at both points in time. In contrast, while about $4 \%$ of the overall sample remained in the most precarious group at both points in time, slightly more males (about 7\%), and slightly fewer females (about 2\%) remained in this group at both points in time. 
The biggest differences between the groups, again, was in the middle-or semiprecarious - groups, highlighted in medium gray. While $18 \%$ of the overall sample was in semi-precarious employment at both points in time, fewer males (approximately 9\%) remained in semi-precarious employment, while about $22 \%$ of females remained in semiprecarious employment at both points in time.

Table 3. Change in Precarious Employment from Wave III to Wave IV

\begin{tabular}{|c|c|c|c|c|}
\hline All & & \multicolumn{3}{|c|}{ Wave IV } \\
\hline \multirow{4}{*}{ 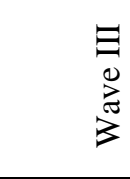 } & \multirow{4}{*}{$\begin{array}{l}\text { Least } \\
\text { Semi } \\
\text { Most }\end{array}$} & Least & Semi & Most \\
\hline & & 26.4 & 9.9 & 2.8 \\
\hline & & 26.2 & 18.0 & 4.7 \\
\hline & & 4.8 & 3.0 & 4.2 \\
\hline \multirow{5}{*}{ 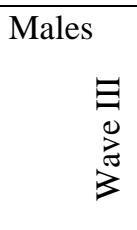 } & \multirow{5}{*}{$\begin{array}{l}\text { Least } \\
\text { Semi } \\
\text { Most }\end{array}$} & \multicolumn{3}{|c|}{ Wave IV } \\
\hline & & Least & Semi & Most \\
\hline & & 31.6 & 4.6 & 4.0 \\
\hline & & 29.7 & 9.1 & 5.7 \\
\hline & & 6.7 & 2.0 & 6.6 \\
\hline \multirow{5}{*}{ 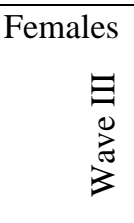 } & \multirow{5}{*}{$\begin{array}{l}\text { Least } \\
\text { Semi } \\
\text { Most }\end{array}$} & & Wave I & \\
\hline & & Least & Semi & Most \\
\hline & & 24.9 & 11.4 & 1.8 \\
\hline & & 28.1 & 21.5 & 3.9 \\
\hline & & 3.8 & 2.9 & 1.9 \\
\hline
\end{tabular}

Key:

Least precarious at both waves (no change)

Moved away from precarity from Wave III to Wave IV

Semi precarious at both waves (no change)

Moved further into precarity from Wave III to Wave IV

Most precarious at both waves (no change)

The changes in level of precarious employment from Wave III to Wave IV are above the diagonal (representing moving further into precarious employment or getting worse) and below the diagonal (representing moving away from precarious employment or getting better). While about $17 \%$ of the overall sample moved further into precarity, fewer males (about 14\%) and the same percentage of females (about 17\%) did So. Similarly, while about $34 \%$ of the overall sample moved away from precarity, a greater percentage of males (about 38\%) and the same percentage of females (34\%) did. In other words, higher percentages of males than females improved their employment status over time, and lower percentages of males got worse.

In order to assess whether there was a significant difference in the patterns of internal change from Wave III to Wave IV, Bowker's test of symmetry was conducted for the overall sample and separately for males and females. In each case, it was significant ( $p<$ .05 ), indicating that there were significant differences in the patterns of internal change for the overall sample, males, and females. 
From there, Bonferroni post-hoc tests were conducted, in order to compare the various patterns of movement from Wave III to Wave IV, and identify any significant differences. Table 4 presents the test statistics using the $\mathrm{Z}$ distribution that were generated from these tests, as well as a key indicating each of the comparisons that were conducted. These results suggest that, overall, the various types of shifts over time captured in Tables 3 through 5 were significantly different from each other. The implications of these differences are explored in the Discussion.

Table 4. Post hoc tests of internal change

\begin{tabular}{llc}
\hline \multirow{2}{*}{ Total } & \multicolumn{1}{c}{ Shift } & $\mathrm{z}$ \\
\cline { 2 - 3 } & a-Comparison of 1-level shifts at lower levels of precarity & $21.0^{*}$ \\
& b-Comparison of 2-level shifts between lowest and highest levels of precarity & $5.6^{*}$ \\
& c-Comparison of 1-level shifts at higher levels of precarity & $-4.7^{*}$ \\
\hline \multirow{2}{*}{ Males } & a-Comparison of 1-level shifts at lower levels of precarity & $23.5^{*}$ \\
& b-Comparison of 2-level shifts between lowest and highest levels of precarity & $4.6^{*}$ \\
& c-Comparison of 1-level shifts at higher levels of precarity & -7.3 \\
\hline \multirow{2}{*}{ Females } & a-Comparison of 1-level shifts at lower levels of precarity & $14.5^{*}$ \\
& b-Comparison of 2-level shifts between lowest and highest levels of precarity & $4.6^{*}$ \\
& c-Comparison of 1-level shifts at higher levels of precarity & -2.1 \\
\hline$* \mathrm{p} \leq .05$ & &
\end{tabular}

Key for post hoc comparisons

\begin{tabular}{|c|l|c|c|c|}
\hline \multicolumn{2}{|c|}{} & \multicolumn{3}{|c|}{ Wave IV } \\
\cline { 3 - 5 } \multicolumn{2}{c|}{} & $\begin{array}{c}\text { Least } \\
\text { precarious }\end{array}$ & $\begin{array}{c}\text { Semi } \\
\text { precarious }\end{array}$ & $\begin{array}{c}\text { Most } \\
\text { precarious }\end{array}$ \\
\hline \multirow{3}{*}{ Wave III } & Least precarious & & $\mathrm{a}$ & $\mathrm{b}$ \\
\cline { 2 - 5 } & Semi precarious & $\mathrm{a}$ & & $\mathrm{c}$ \\
\cline { 2 - 5 } & Most precarious & $\mathrm{b}$ & $\mathrm{c}$ & \\
\hline
\end{tabular}

In summary, findings from the study indicated that high percentages of young people (about $49 \%$ of the overall sample) were in the semi-precarious employment category at Wave III, while about $39 \%$ were in the least precarious category, and about $12 \%$ were in the most precarious category. Slightly higher percentages of females than males were in the semi-precarious employment category, and slightly lower percentages of women were found to be in the most precarious category. There were significant shifts in precarious employment levels from Wave III to Wave IV, both for the overall sample and when males and females were analyzed separately. Overall, higher percentages of females than males remained in semi-precarious employment over time. On the flip side, higher percentages of males were located at the extremes - where they either moved deeper into precarity, or moved away from precarity over time. 


\section{Discussion}

This study contributes new insight into precarious employment trajectories for young men and women in the United States. Overall, findings provide support for the hypotheses that higher percentages of young women than men would be in precarious employment at the initial time point, and that higher percentages of women would have difficulty moving out of precarious employment over time. In light of findings from previous studies, several additional interesting points emerged.

First, there were three groups with varying levels of precarity at each time point: a least precarious group, a semi-precarious group, and a most precarious group. This finding aligned with previous literature suggesting that precarious employment exists on a continuum (Cranford \& Vosko, 2006).

A second finding of note was that, in contrast with previous studies that used a single, dichotomous measure such as the 2005 Contingent Worker Supplement, which found that about $27 \%$ of young workers would be considered contingent workers (BLS, 2005), this study found a relatively low percentage of young people who were in the most precarious group - only about $12 \%$. One explanation for this lower proportion could be that some of the most precarious workers worked less than 10 hours a week at one or both waves of data collection, and were thus excluded from the study. Alternatively, it may be due to the categorization scheme used in the analyses, which grouped workers into three groups instead of two. Almost half of the study participants, when they were between the ages of 18 to 26 , were in jobs that would be considered semi-precarious. This raises the question: how might the experiences of people in this group differ from those captured in previous studies that used single measures of precarious or non-precarious work?

Another interesting finding was related to the gender differences in patterns of precarious employment over time. Higher percentages of women, compared to men, remained in semi-precarious employment over time. In light of existing research on gender inequalities in employment, this finding might be interpreted as one of the possible ways in which inequality manifests early, and sets the stage for lifelong barriers to opportunities in employment. Similar to the wage "scarring" effect of sub-optimal early experiences in the labor market, it may be that remaining in semi-precarious employment over time early in one's career could contribute to a job quality "scarring" effect, which could lead to challenges to advancing in the workplace over time. This effect may be particularly damaging for women, who have lower rates of advancement and compensation in the workplace (Welle \& Heilman, 2007).

While this study represents one step toward assessing gender differences in precarious employment trajectories for young people, findings suggest that there is a need for a range of policy and practice interventions to promote more equitable employment outcomes, as suggested by other precarious employment researchers (e.g., Quinlan et al., 2010). One way to address differences in precarious employment by gender would be to implement and enforce national-level policies to ensure that women receive fair treatment and compensation in the workplace. Several such policies have been proposed in the past year, including the Paycheck Fairness Act (Congress.gov, 2019), which would strengthen the enforcement of anti-discrimination efforts and prohibit retaliation against workers who 
discuss wages, and the Pay Equity for All Act, which would prohibit employers from asking potential employees about their employment and benefits history (Congress.gov, 2019; Lerum, 2013). In addition, there are numerous other national-level strategies that could be used to address the precariousness of work, such as raising the national minimum wage and improving access to healthcare, regardless of employment status. Alternatively, or in addition, policymakers could choose to create legislation to protect workers from insecurity during employment transitions due to losing a job, taking leave after the birth of a child, or changing occupations, as suggested by scholars such as Kalleberg and Vallas (2018).

These findings also have implications for social work practitioners who work directly with young people. While these practitioners (and clients) are limited by the number and quality of jobs available, there may be some potential strategies to explore. First, this study points to the importance of helping young men and women to get onto career pathways that can help them to avoid remaining stuck in precarious work. Previous research has found that gender-related differences in occupational aspirations, as well as job-related skills and credentials, contributes to the gender wage gap during the period of career entry (Marini \& Fan, 1997). In addition, gender-based differences in earnings have been found to increase over time (Goldin, 2014). Therefore, it is critical for practitioners to help young women and men onto pathways to non-precarious jobs during this time.

In addition, social workers can engage in advocacy to improve the quality of jobs available, either through a change in policy or through the creation of new social programs. These macro-level changes are necessary, in light of previous research that suggests that while voluntary action can be taken by employers to develop equitable policies and practices, these actions may not fully address problems around gender inequality in the workplace (e.g., Lambert, 1993). Therefore, social workers should consider supporting innovative strategies taking place at the state and local level currently, which could be expected to have an effect on the number of young people in precarious employment. For example, in several cities, such as San Francisco and New York City, "fair workweek" legislation has been passed that has created protections for certain groups of workers, to require employers to create predictable work schedules. Legislation such as this may help to reduce the precariousness associated with jobs in certain industries, such as fast food and retail. They can also support efforts to improve employment in particular occupations, such as home health care work and domestic work (Boris \& Klein, 2006; Poo, 2011).

While this study provides some initial findings around gender and precarious employment in young people, it also has several important limitations. First, some of the dimensions of job quality that were used to create the precarious employment variables were measured indirectly. For example, job security was measured based on the likelihood of alternative work arrangements in the respondent's occupational category, rather than a more direct measure of job insecurity in which the respondent was asked about their likelihood of losing his or her job. Similarly, this study used a variable for whether the study participant received health insurance through his or her employer to represent access to employer-provided benefits, a key aspect of precarious work. There may be better measures of access to employer-provided benefits that could be used in future studies of precarious employment, particularly for studies focusing on emerging adults. In addition, 
this study used data that were collected prior to, and at the beginning of, the recent economic recession. Therefore, while the issue of precarious employment is relevant to young people in the United States today, the findings from this study are only generalizable to young people who worked at least ten hours a week in 2001/2002 and 2008/2009. Data gathered toward the end of or after the recession might show that many young people from this study lost their jobs during that time, particularly those from groups that were the most affected-men, the less educated, and African Americans (Kalleberg \& Von Wachter, 2017). Post-recession data show that many young people have either dropped out of the labor market, or to obtained jobs at a higher level of precariousness. Lastly, this article focuses on paid work, and does not include unpaid work, which could have added an important dimension to the discussion of precarious employment (Pulignano, 2019).

This study points to several directions for future research on gender and precarious work. For example, it would be helpful for future research to gather data with the specific purpose of assessing precarious employment over time and that includes each of the four dimensions suggested by precarious employment theorists. In addition, future studies could gather data on young people's decision-making around employment, and the ways in which those in precarious employment may access resources from other sources, such as family members and friends. Lastly, researchers could use qualitative methods to explore young people's understanding of the employment opportunities available to them, the challenges some young people face in obtaining employment, and the strategies that are being used to overcome these challenges.

\section{References}

Add Health. (n.d.). Data. https://addhealth.cpc.unc.edu/data/

Alterman, T., Luckhaupt, S. E., Dahlhamer, J. M., Ward, B. W., \& Calvert, G. M. (2013). Job insecurity, work-family imbalance, and hostile work environment: Prevalence data from the 2010 National Health Interview Survey. American Journal of Industrial Medicine, 56(6), 660-669. https://doi.org/10.1002/ajim.22123

Arnett, J. J. (2000). Emerging adulthood: A theory of development from the late teens through the twenties. American Psychologist, 55(5), 469-480. https://doi.org/10.1037/0003-066x.55.5.469

Benach, J., Vives, A., Tarafa, G., Delclos, C., \& Muntaner, C. (2016). What should we know about precarious employment and health in 2025? Framing the agenda for the next decade of research. International Journal of Epidemiology, 45(1), 232-238. doi:https://doi.org/10.1093/ije/dyv342

Bernhardt, A., \& Osterman, P. (2017). Organizing for good jobs: Recent developments and new challenges. Work and Occupations, 44(1), 89-112. doi:https://doi.org/10.1177/0730888415625096

Blau, F. D., \& Kahn, L. M. (2007). The gender pay gap: Have women gone as far as they can? Academy of Management Perspectives, 21(1), 7-23. https://doi.org/10.5465/amp.2007.24286161 
Boris, E., \& Klein, J. (2006). Organizing home care: Low-waged workers in the welfare state. Politics \& Society, 34(1), 81-108. https://doi.org/10.1177/0032329205284757

Boushey, H. (2005). No way out: How prime-age workers get trapped in minimum-wage jobs. WorkingUSA, 8(6), 659-670. https://doi.org/10.1111/j.1743-4580.2005.00076.x

Bowker, A. H. (1948). A test for symmetry in contingency tables. Journal of the American Statistical Association, 43, 572-574. https://doi.org/10.1080/01621459.1948.10483284

Carré, F., \& Heintz, J. (2009). The United States: Different sources of precariousness in a mosaic of employment arrangements. In L. F. Vosko, M. MacDonald, \& I Campbell (Eds.), Gender and the contours of precarious employment (pp. 43-59). Routledge. https://doi.org/10.4324/9780203874424

Cech, E. A. (2016). Mechanism or myth? Family plans and the reproduction of occupational gender segregation. Gender \& Society, 30(2), 265-288. https://doi.org/10.1177/0891243215608798

Chan, S., \& Tweedie, D. (2015). Precarious work and reproductive insecurity. Social Alternatives, 34(4), 5-13

Chen, P., \& Chantala, K. (2014). Guidelines for analyzing Add Health data. Carolina Population Center, University of North Carolina at Chapel Hill, 1-53.

Chirkova, S. (2019). The impact of parental leave policy on child-rearing and employment behavior: The case of Germany. IZA Journal of Labor Policy, 9(1), 127. https://doi.org/10.2478/izajolp-2019-0007

Congress.gov. (2019). H.R.1864 - Pay Equity for All Act of 2019. https://www.congress.gov/bill/116th-congress/house-bill/1864/all-info

Cranford, C. J., \& Vosko, L. F. (2006). Conceptualizing precarious employment: Mapping wage work across social location and occupational context. In Precarious employment: Understanding labour market insecurity in Canada (pp. 43-66). McGill-Queen's University Press.

Cranford, C., Vosko, L., \& Zukewich, N. (2003). The gender of precarious employment in Canada. Relations Industrielles/Industrial Relations, 58(3), 454-482. https://doi.org/10.7202/007495ar

Dunn, O. J. (1961). Multiple comparisons among means. Journal of the American Statistical Association, 56(293), 52-64.

Frade, C., Darmon, I., \& Laparra, M. (2004). Precarious employment in Europe: A comparative study of labour market related risk in flexible economies. Esope Project, European Commission. http://ec.europa.eu/research/socialsciences/pdf/finalreport/hpse-ct-2001-00075-final-report.pdf

García-Pérez, C., Prieto-Alaiz, M., \& Simón, H. (2017). A new multidimensional approach to measuring precarious employment. Social Indicators Research, 134(2), 437-454. https://doi.org/10.1007/s11205-016-1447-6 
Glatt, J., \& Wunnava, P. V. (2018). Help not wanted: The dismal science of youth unemployment's scarring effect. iBusiness, 10, 51-84 https://doi.org/10.4236/ib.2018.102004

Goldin, C. (2014). A grand gender convergence: Its last chapter. American Economic Review, 104(4), 1091-1119. https://doi.org/10.1257/aer.104.4.1091

Goldin, C., Kerr, S. P., Olivetti, C., \& Barth, E. (2017). The expanding gender earnings gap: Evidence from the LEHD-2000 Census. American Economic Review, 107(5), 110-114. https://www.aeaweb.org/articles?id=10.1257/aer.p20171065

Haas, L., \& Hwang, C. P. (2008). The impact of taking parental leave on fathers' participation in childcare and relationships with children: Lessons from Sweden. Community, Work and Family, 11(1), 85-104. https://doi.org/10.1080/13668800701785346

Harris, K. M. (2009). The National Longitudinal Study of Adolescent to Adult Health (Add Health), Waves I \& II, 1994-1996; Wave III, 2001-2002; Wave IV, 2007-2009 [machine-readable data file and documentation]. Chapel Hill, NC: Carolina Population Center, University of North Carolina at Chapel Hill. https://www.cpc.unc.edu/projects/addhealth/faqs/addhealth/index.html\#how-do-icite-design

Hegewisch, A., \& Gornick, J. C. (2011). The impact of work-family policies on women's employment: A review of research from OECD countries. Community, Work \& Family, 14(2), 119-138. https://doi.org/10.1080/13668803.2011.571395

Hegewisch, A., Liepmann, H., Hayes, J., \& Hartmann, H. (2010). Separate and not equal? Gender segregation in the labor market and the gender wage gap. Institute for Women's Policy Research Briefing Paper, 377, 1-16. https://iwpr.org/wpcontent/uploads/wpallimport/files/iwpr-export/publications/C377.pdf

Hout, M. (2019). The employment patterns of young adults, 1989-2014. In L. S. Chancer, M. Sánchez-Jankowski, \& C. Trost (Eds.), Youth, jobs, and the future: Problems and prospects (pp. 19-34). Oxford University Press. https://doi.org/10.1093/oso/9780190685898.001.0001

Kaiser Family Foundation. (2017). Key facts about the uninsured population. https://www.kff.org/uninsured/fact-sheet/key-facts-about-the-uninsured-population/

Kalleberg, A. L. (2000). Nonstandard employment relations: Part-time, temporary and contract work. Annual Review of Sociology, 26(1), 341-365. https://doi.org/10.1146/annurev.soc.26.1.341

Kalleberg, A. L. (2009). Precarious work, insecure workers: Employment relations in transition. American Sociological Review, 74(1), 1-22. https://doi.org/10.1177/000312240907400101

Kalleberg, A. L. (2019). Precarious Work and Young Workers in the United States. In L. S. Chancer, M. Sánchez-Jankowski, \& C. Trost (Eds.), Youth, jobs, and the future: 
Problems and prospects (pp. 35-54). New York, NY: Oxford University Press. https://doi.org/10.1093/oso/9780190685898.001.0001

Kalleberg, A. L., \& Vallas, S. P. (2018). Probing precarious work: Theory, research, and politics. Research in the Sociology of Work, 31, 1-30. https://doi.org/10.1108/s0277283320170000031017

Kalleberg, A. L., \& Von Wachter, T. M. (2017). The U.S. labor market during and after the Great Recession: Continuities and transformations. RSF: The Russell Sage Foundation Journal of the Social Sciences, 3(3), 1-19. https://doi.org/10.7758/rsf.2017.3.3.01

Katz, L. F., \& Krueger, A. B. (2016). The rise and nature of alternative work arrangements in the United States, 1995-2015 (No. w22667). National Bureau of Economic Research. https://doi.org/10.3386/w22667

Kletzer, L. G., \& Fairlie, R. (1999). The long-term costs of job displacement among young workers. Northwestern University/University of Chicago Joint Center for Poverty Research.

Lambert, S. J. (1993). Workplace policies as social policy. Social Service Review, 67(2), 237-260. https://doi.org/10.1086/603980

Lambert, S. J., \& Henly, J. R. (2014). Measuring Precarious Work Schedules. University of Chicago. EINet Working Paper. https://ssa.uchicago.edu/sites/default/files/uploads/managingprecariousworkschedule s_11.11.2015.pdf

Lerum, C. (2013). Equal pay for women can become a reality: A proposal for enactment of the Paycheck Fairness Act. https://commons.lib.niu.edu/handle/10843/18493

Mandel, H., \& Semyonov, M. (2005). Family policies, wage structures, and gender gaps: Sources of earnings inequality in 20 countries. American Sociological Review, 70(6), 949-967. https://doi.org/10.1177/000312240507000604

Marini, M. M., \& Fan, P. L. (1997). The gender gap in earnings at career entry. American Sociological Review, 62 (4),588-604. https://doi.org/10.2307/2657428

McCutcheon, A. L. (1987). Latent class analysis. Newbury Park, CA: Sage .

Mroz, T. A., \& Savage, T. H. (2006). The long-term effects of youth unemployment. Journal of Human Resources, 41(2), 259-293.

Muthén, L. K., \& Muthén, B. O. (1998-2011). Mplus User's Guide (6th ed.). Los Angeles, CA: Authors.

Nylund, K., Asparouhov, T., \& Muthén, B. (2007). Deciding on the number of classes in latent class analysis and growth mixture modeling: A Monte Carlo simulation study. Structural Equation Modeling, 14, 535-569. https://doi.org/10.1080/10705510701575396 
Osgood, D. W., Foster, E. M., Flanagan, C., \& Ruth, G. R. (Eds). (2005). Introduction: Why Focus on the Transition to Adulthood for Vulnerable Populations? In On your own without a net: The transition to adulthood for vulnerable populations (pp. 1-26). University of Chicago Press. https://doi.org/10.7208/chicago/9780226637853.001.0001

Poo, A. J. (2011). A twenty-first century organizing model: Lessons from the New York Domestic Workers Bill of Rights campaign. New Labor Forum, 20(1), 51-55. https://doi.org/10.4179/nlf.201.0000008

Pulignano, V. (2019). Work in deregulated labour markets: A research agenda for precariousness. ETUI Research Paper-Working Paper. https://doi.org/10.2139/ssrn.3350980

Quinlan, M., Mayhew, C., \& Bohle, P. (2001). The global expansion of precarious employment, work disorganization, and consequences for occupational health: placing the debate in a comparative historical context. International Journal of Health Services, 31(3), 507-536. https://doi.org/10.2190/22bk-9xc0-ak71-m6qh

Quinlan, M., Muntaner, C., Solar, O., Vergara, M., Eijkemans, G., Santana, V., Chung, H., Castedo, A., Benach, J., \& EMCONET Network. (2010). Policies and interventions on employment relations and health inequalities. International Journal of Health Services, 40(2), 297-307. https://doi.org/10.2190/hs.40.2.i

Rodgers, G. (1989). Precarious work in Western Europe: The state of the debate. In G. Rodgers \& J. Rodgers (Eds.), Precarious jobs in labour market regulation: The growth of atypical employment in Western Europe. International Labour Organisation. https://doi.org/10.4337/9781784715755

Shaffer, M. A., Joplin, J. R., Bell, M. P., Lau, T., \& Oguz, C. (2000). Gender discrimination and job-related outcomes: A cross-cultural comparison of working women in the United States and China. Journal of Vocational Behavior, 57(3), 395427. https://doi.org/10.1006/jvbe.1999.1748

Toossi, M. (2002). A century of change: The US labor force, 1950-2050. Monthly Labor Review, May 2002, 15-28. https://www.bls.gov/opub/mlr/2002/05/art2full.pdf

U.S. Bureau of Labor Statistics. (2005). Contingent and alternative employment arrangements, February 2005. https://www.bls.gov/news.release/history/conemp.txt

U.S. Bureau of Labor Statistics. (2015). Worker's expectations about losing and replacing their jobs: 35 years of change. https://doi.org/10.21916/mlr.2015.1

U.S. Bureau of Labor Statistics. (2018). Contingent and alternative employment arrangements. https://www.bls.gov/news.release/pdf/conemp.pdf

Vosko, L. F., \& Clarke, L. F. (2009). Canada: Gendered precariousness and social reproduction. In L. F. Vosko, M. MacDonald, M., \& I. Campbell (Eds.), Gender and the contours of precarious employment (pp. 26-42). Routledge. https://doi.org/10.4324/9780203874424 
Vosko, L. F., MacDonald, M., \& Campbell, I. (Eds.). (2009). Gender and the contours of precarious employment. NY: Routledge. https://doi.org/10.4324/9780203874424

Welle, B., \& Heilman, M. E. (2007). Formal and informal discrimination against women at work: The role of gender stereotypes. In S. W. Gilliland, D. D. Steiner, \& D. P. Skarlicki (Eds.), Research in social issues in management: Managing social and ethical issues in organizations (pp. 229-252). USA: Information Age.

Author note: Address correspondence to Dr. Skye Allmang, Rutgers School of Social Work, 120 Albany Street, Tower One - Suite 200, New Brunswick, NJ 08901. E-mail: skye.allmang@rutgers.edu

Acknowledgements: This research uses data from Add Health, a program project directed by Kathleen Mullan Harris and designed by J. Richard Udry, Peter S. Bearman, and Kathleen Mullan Harris at the University of North Carolina at Chapel Hill, and funded by grant P01-HD31921 from the Eunice Kennedy Shriver National Institute of Child Health and Human Development, with cooperative funding from 23 other federal agencies and foundations. Special acknowledgment is due Ronald R. Rindfuss and Barbara Entwisle for assistance in the original design. No direct support was received from grant P01-HD31921 for this analysis. 